Original Article

\title{
Complications after video-assisted thoracic surgery in patients with pulmonary nontuberculous mycobacterial lung disease who underwent preoperative pulmonary rehabilitation
}

\author{
Akira Morino, PT, MS ${ }^{1 *}$, Kazuma Murase, PT, $\mathrm{MS}^{2)}$, Katsuo Yamada, MD, PhD ${ }^{3)}$ \\ 1) Department of Physical Therapy, Hokkaido Chitose Institute of Rehabilitation Technology: \\ 10 Satomi 2-chome, Chitose, Hokkaido 066-0055, Japan \\ 2) Department of Physical Therapy, National Organization Hospital Higashinagoya National Hospital, \\ Japan \\ 3) Department of Thoracic Surgery, National Organization Hospital Higashinagoya National Hospital, \\ Japan
}

\begin{abstract}
Purpose] Video-assisted thoracic surgery and preoperative pulmonary rehabilitation are effective in preventing postoperative complications in patients with cardiopulmonary disease. The present study aims to elucidate the presence of postoperative pneumonia and atelectasis in patients with nontuberculous mycobacterial lung disease who underwent lung resection with video-assisted thoracic surgery and preoperative pulmonary rehabilitation. [Subjects and Methods] Nineteen patients with nontuberculous mycobacterial lung disease who had undergone lung resection with video-assisted thoracic surgery and preoperative pulmonary rehabilitation were enrolled in this study. The presence of postoperative pneumonia and atelectasis was evaluated, and preoperative and postoperative pulmonary functions were compared. [Results] Postoperative pneumonia and postoperative atelectasis were not observed. Decreases of pulmonary function were 5.9\% (standard deviation, 8.5 ) in forced vital capacity (percent predicted) and 9.6\% (standard deviation, 11.1) in forced expiratory volume in $1 \mathrm{~s}$ (percent predicted). [Conclusion] The present study indicates that the combination of lung resection with video-assisted thoracic surgery and preoperative pulmonary rehabilitation in patients with nontuberculous mycobacterial lung disease may be effective in preventing postoperative complications.

Key words: Nontuberculous mycobacteria, Video-assisted thoracic surgery, Complication
\end{abstract}

(This article was submitted Apr. 2, 2015, and was accepted May 15, 2015)

\section{INTRODUCTION}

Nontuberculous mycobacterial (NTM) lung disease is a chronic pulmonary infection in the lung and its branches, and is caused by anti-fast bacilli other than tuberculous mycobacteria $^{1)}$. Often, there is no symptom in the early stage of this disease. As the disease progresses, respiratory symptoms (e.g., cough and sputum), fever, and weight loss appear. The incidence rate of NTM was about 2.0 cases per 100,000 persons in the United States in $2008^{2}$. In a recent study, the incidence rates in Japan increased from 2.43 cases per 100,000 persons in 1990 to 5.7 cases per 100,000 persons in $2007^{3)}$.

The main treatment of NTM lung disease is chemotherapy. In some cases, a surgical procedure is combined with

\footnotetext{
*Corresponding author. Akira Morino (E-mail: a-morino@,
} chitose-reha.ac.jp)

(C2015 The Society of Physical Therapy Science. Published by IPEC Inc. This is an open-access article distributed under the terms of the Creative Commons Attribution Non-Commercial No Derivatives (by-ncnd) License $<$ http://creativecommons.org/licenses/by-nc-nd/3.0/> . chemotherapy. ATS/IDSA guideline recommends the combination of chemotherapy and surgical procedures for NTM lung disease patients with resectable lesions. The Japanese guideline of the surgical procedure for NTM recommends that surgical procedures are applied to smear-positive NTM lung disease patients or those with localized lesions despite undergoing chemotherapy ${ }^{4}$. Video-assisted thoracic surgery (VATS) is one of such surgical procedures. On average, this procedure leads to less postoperative wounds, postoperative pain, and complications, and a shorter length of hospital stay than thoracotomy in patients with lung cancer ${ }^{5-8)}$. In some hospitals, VATS is performed for NTM lung disease patients.

Preoperative pulmonary rehabilitation for lung resection surgery (pre-PR) consists of respiratory muscle training, aerobic exercise, instructions on breathing technique, phlegm expulsion technique, and activities of daily living after the operation. Whereas there are some reports about preoperative pulmonary rehabilitation ${ }^{9,10)}$, pre-PR has very little empirical evidence. Few reports have shown that prePR decreases postoperative complications and length of hospital stay ${ }^{11)}$.

Pre-PR was performed on NTM lung disease patients who underwent lung resection with VATS at our hospital, 
Table 1. Characteristics of the 19 patients

\begin{tabular}{lc}
\hline Variables & Values \\
\hline Age, years ${ }^{\dagger}$ & $52.1 \pm 13.8$ \\
Gender M/F, $\mathrm{n}$ & $5 / 14$ \\
$\mathrm{BMI}, \mathrm{kg} / \mathrm{m}^{2}{ }^{\dagger}$ & $20.4 \pm 1.9$ \\
Strain of mycobacterium, $\mathrm{n}(\%)$ & \\
M. avium & $13(68.4)$ \\
M. intracellulare & $4(21.1)$ \\
M. abscessus & $1(5.3)$ \\
M. xenopi & $1(5.3)$ \\
Medication, n (\%) & \\
CAM & $19(100.0)$ \\
REF & $17(89.5)$ \\
EB & $17(89.5)$ \\
KM & $12(63.2)$ \\
STFX & $2(10.5)$ \\
Surgical procedure, n (\%) & \\
Lobectomy & $10(52.6)$ \\
Segmentectomy & $3(15.8)$ \\
Partial resection & $2(10.5)$ \\
Bi-lobectomy & $2(10.5)$ \\
Lobectomy + partial resection & $1(5.3)$ \\
Segmentectomy + partial resection & $1(5.3)$ \\
\hline$\dagger$ Values are expressed as mean \pm SD. \\
BMI: body mass index; CAM: clarithromycin; REF, rifam- \\
picin; EB: ethambutol; KM: kanamycin; STFX: sitafloxacin
\end{tabular}

because it was deemed that a combination of VATS and prePR may be effective in preventing postoperative pneumonia and atelectasis. To the best of our knowledge, there have been no reports on complications after lung resection with VATS in NTM lung disease patients who underwent pre-PR.

Thus, in the present study, we aimed to detect the occurrence of postoperative pneumonia and atelectasis in NTM lung disease patients who underwent lung resection with VATS and pre-PR, and to investigate the difference between preoperative and postoperative pulmonary functions.

\section{SUBJECTS AND METHODS}

\section{Subjects}

NTM lung disease patients who underwent lung resection with VATS at the National Hospital Organization Higashi Nagoya National Hospital between April in 2013 and March in 2014 were enrolled. The following patients were excluded: those who had cognitive disorder and those who had a disease (e.g., musculoskeletal disease, cerebrovascular disease, or neuromuscular disease) that seriously impaired the function of walking before the operation. Twenty patients were screened, and one patient who did not undergo the test for postoperative pulmonary function was excluded. Nineteen patients were thereby analyzed. NTM lung disease was diagnosed according to the Japanese guideline for the diagnosis of this disease ${ }^{12)}$.

This retrospective observational study was conducted according to the clinical study ethics guidelines.
Table 2. Results of postoperative complications and progress

\begin{tabular}{lc}
\hline Complications and progress & Values \\
\hline Complications, $\mathrm{n}$ & 0 \\
Atelectasis & 0 \\
Pneumonia & $1.0(1.0-2.0)$ \\
Number of days before independent gait, days & $6.0(6.0-7.0)$ \\
Number of days in hospital, days & \multicolumn{2}{l}{ Values are expressed as median (interquartile range) }
\end{tabular}

\section{Methods}

Data including the subjects' age, gender, strain of mycobacterium, chemotherapy before the operation, number of days before independent gait, and number of days in hospital assessed as postoperative variables, were collected from the subjects' medical records. The patients underwent high-resolution computed tomography and pulmonary function tests. The pulmonary function test was performed at preoperation and at postoperative 3 months.

Pre-PR was carried out once before the operation, and it took about $40 \mathrm{~min}$. Pre-PR consisted of instructions about breathing technique, respiratory muscle training by using incentive spirometry, active cycle breathing technique, activities of daily living after the operation, and aerobic exercise. The patients were instructed that pre-PR, as a home-based exercise, should be performed during the preoperative period from the day of receiving the instructions.

Postoperative pneumonia and atelectasis were assessed as postoperative complications according to the Common Terminology Criteria for Adverse Events ver.4.0 ${ }^{13}$. Grade 1 or higher in this criteria was defined as the presence of postoperative complication.

To compare preoperative and postoperative pulmonary function, a paired t-test was performed. SPSS software version 19 (SPSS Japan Inc., Tokyo, Japan) was used for statistical processing, and the significance level for each analysis was set at 5\%.

\section{RESULTS}

Table 1 shows the characteristics of the 19 patients. The duration between the day of the instructions of the pre-PR and the day of the operation was 51.4 days (standard deviation [SD], 32.4). All patients had no postoperative pneumonia and atelectasis.

The postoperative progress is shown in Table 2 . The median number of days before independent gait and the days of hospital stay are 1.0 day (interquartile range, 1.0-2.0) and 6.0 days (interquartile range, 6.0-7.0), respectively.

The results of the comparison of preoperative and postoperative pulmonary functions are shown in Table 3 . We identified a significant difference in forced vital capacity $(\mathrm{FVC})$ and forced expiratory volume in $1 \mathrm{~s}\left(\mathrm{FEV}_{1}\right)$. The differences between preoperative and 3 months postoperative pulmonary function were $-5.9 \%$ (SD: 8.5 ) in FVC \% predicted and $-9.6 \%$ (SD: 11.1 ) in $\mathrm{FEV}_{1} \%$ predicted. 
Table 3. Differences of pulmonary functions between preoperation and at 3 months postoperation

\begin{tabular}{lcc}
\hline Variables & Preoperation & $\begin{array}{c}\text { Three months } \\
\text { postoperation }\end{array}$ \\
\hline VC, liters & $3.2 \pm 0.9$ & $3.2 \pm 0.9$ \\
VC, \% predicted & $109.0 \pm 14.3$ & $109.7 \pm 13.6$ \\
FVC, liters ** & $3.2 \pm 0.9$ & $3.0 \pm 0.8$ \\
FVC, \% predicted ** & $109.3 \pm 14.5$ & $102.6 \pm 14.7$ \\
$\mathrm{FEV}_{1}$, liters $* * *$ & $2.5 \pm 0.7$ & $2.3 \pm 0.6$ \\
$\mathrm{FEV}_{1}, \%$ predicted $* *$ & $105.7 \pm 22.2$ & $94.8 \pm 19.6$ \\
$\mathrm{FEV}_{1} / \mathrm{FVC}, \%$ & $80.2 \pm 9.0$ & $77.2 \pm 7.9$ \\
\hline
\end{tabular}

Values are expressed as mean $\pm \mathrm{SD}$.

$* * \mathrm{p}<0.01 ; * * * \mathrm{p}<0.001$.

$\mathrm{VC}$ : vital capacity; FVC: forced vital capacity; $\mathrm{FEV}_{1}$ : forced expiratory volume in $1 \mathrm{~s}$

\section{DISCUSSION}

In this study, we investigated the presence of postoperative pneumonia and atelectasis in NTM lung disease patients who underwent lung resection with VATS and pre-PR. We found no patients with preoperative pneumonia and atelectasis.

Algar et al. reported that the incidences of postoperative pneumonia and atelectasis in lung cancer patients who underwent resection with VATS were $3.3 \%$ and $2.9 \%$, respectively ${ }^{14)}$. The results of the present study were better than those of the study by Algar et al. Previous studies have revealed that age and preoperative pulmonary function affect the occurrence of complications after lung resection ${ }^{15}$. The susceptible age for NTM lung disease is lower than that for lung cancer. Consequently, the preoperative pulmonary function of NTM lung disease patients is often better than that of lung cancer patients. Because lymphadenectomy was not performed in the lung resection surgery for NTM lung disease, the surgery for NTM lung disease was considered to be low invasive. The fact that the incidence of postoperative complications in NTM lung disease was lower than that in lung cancer was inferred from those reasons. Our results were supported by a previous study of Yu et al. that revealed that the incidence of postoperative pneumonia and atelectasis in NTM lung disease patients who underwent resection surgery with VATS were $1.2 \%$ and $0.6 \%$, respectively ${ }^{16)}$.

Benzo et al. reported that the incidence of postoperative complications in lung cancer patients who underwent prePR was significantly lower than that in patients who received usual care ${ }^{11)}$. Moreover, Varela et al. elucidated that the combination of respiratory muscle training by using an incentive spirometry and peripheral muscle training at pre-PR was more effective for the prevention of postoperative atelectasis than respiratory muscle training alone ${ }^{17}$. The reasons for the good result - that postoperative pneumonia and atelectasis might be eliminated by pre-PR - included not only respiratory muscle training but also the instruction of mobilization in our study. Because our retrospective and observational study was without controlled subjects, the effect of pre-PR alone was not elucidated in this study.

In this study, the decreases of FVC \% predicted and
$\mathrm{FEV}_{1} \%$ predicted were $5.9 \%(\mathrm{SD}, 8.5)$ and $9.6 \%(\mathrm{SD}, 11.1)$ at 3 months postoperation, respectively. Santombrogio et al. reported that in lung cancer patients who underwent lung lobectomy, decreases at 6 months postoperation of $10.7 \%$ (SD, $4.5)$ in $\mathrm{FVC} \%$ predicted and $9.1 \%(\mathrm{SD}, 10.7)$ in $\mathrm{FEV}_{1} \%$ predicted were observed ${ }^{18)}$. The decline of pulmonary function in NTM lung disease patients who underwent lung resection was similar to that in lung cancer patients.

Our study has some limitations that need to be addressed. First, the number of patients in our study was small because NTM lung disease is a rare disease. Second, the adherence to pre-PR was not evaluated. Finally, in this study, we did not take into account the resection site and its size. Postoperative pulmonary function is also sometimes used as a predicted value that is calculated by using the number of subsegmentectomy and subsegmental bronchial obstructions caused by a tumor ${ }^{19}$ ). Future studies including a larger number of patients and considering those factors are needed.

In conclusion, the present study elucidates that postoperative pneumonia and atelectasis did not occur in NTM lung disease patients who underwent lung resection with VATS and pre-PR. This indicates that the combination of VATS and pre-PR in NTM lung disease patients may be effective for preventing postoperative complications.

\section{REFERENCES}

1) Griffith DE, Aksamit T, Brown-Elliott BA, et al. ATS Mycobacterial Diseases Subcommittee American Thoracic Society Infectious Disease Society of America: An official ATS/IDSA statement: diagnosis, treatment, and prevention of nontuberculous mycobacterial diseases. Am J Respir Crit Care Med, 2007, 175: 367-416. [Medline] [CrossRef]

2) Bodle EE, Cunningham JA, Della-Latta P, et al.: Epidemiology of nontuberculous mycobacteria in patients without HIV infection, New York City. Emerg Infect Dis, 2008, 14: 390-396. [Medline] [CrossRef]

3) Sato S: Pulmonary nontuberculous mycobacterial diseases: an update. Gendai Igaku, 56, 317-324, 2008.

4) The Japanese Society for Tuberculosis: [Guideline for surgical therapy of non-tuberculous acid-fast bacterial infection of the lung: Committee on the Management of Non-Tuberculous Acid-Fast Bacterial Infections of the Lung, the Japanese Society for Tuberculosis]. Kekkaku, 2008, 83: 527528. [Medline]

5) Muraoka M, Oka T, Akamine S, et al.: Video-assisted thoracic surgery lobectomy reduces the morbidity after surgery for stage I non-small cell lung cancer. Jpn J Thorac Cardiovasc Surg, 2006, 54: 49-55. [Medline] [CrossRef]

6) Nagahiro I, Andou A, Aoe M, et al.: Pulmonary function, postoperative pain, and serum cytokine level after lobectomy: a comparison of VATS and conventional procedure. Ann Thorac Surg, 2001, 72: 362-365. [Medline] [CrossRef]

7) Kaseda S, Aoki T, Hangai N, et al.: Better pulmonary function and prognosis with video-assisted thoracic surgery than with thoracotomy. Ann Thorac Surg, 2000, 70: 1644-1646. [Medline] [CrossRef]

8) Zhang Z, Zhang Y, Feng H, et al.: Is video-assisted thoracic surgery lobectomy better than thoracotomy for early-stage non-small-cell lung cancer? A systematic review and meta-analysis. Eur J Cardiothorac Surg, 2013, 44: 407-414. [Medline] [CrossRef]

9) Park D, Jeong J, Lee H: The effects of a self-training physiotherapy program on pulmonary functions, postoperative pulmonary complications and post-thoracotomy pain after lobectomy of patients with lung cancer. $\mathrm{J}$ Phys Ther Sci, 2013, 25: 253-255. [CrossRef]

10) Jeong JH, Yoo WG: Effects of pulmonary rehabilitation education for caregivers on pulmonary function and pain in patients with lung cancer following lung resection. J Phys Ther Sci, 2015, 27: 489-490. [Medline] [CrossRef]

11) Benzo R, Wigle D, Novotny $P$, et al.: Preoperative pulmonary rehabilitation before lung cancer resection: results from two randomized studies. Lung Cancer, 2011, 74: 441-445. [Medline] [CrossRef]

12) The Japanese Society for Tuberculosis and the Japanese Respiratory So- 
ciety: [Guideline for diagnosis of non-tuberculous acid-fast bacterial infection of the lung-2008. Committee on Management of Non-tuberculous Acid-Fast Bacterial Infection of the Japanese Society for Tuberculosis and the Section on Tuberculosis and Infection, the Japanese Respiratory Society]. Kekkaku, 2008, 83: 525-526. [Medline]

13) National Cancer Institute Common Terminology Criteria for Adverse Events ver. 4.0 (CTCAE). http://ctep.cancer.gov/protocolDevelopment/ electronic_applications/ctc.htm. (Accessed Mar. 10, 2015)

14) Algar FJ, Alvarez A, Salvatierra A, et al.: Predicting pulmonary complications after pneumonectomy for lung cancer. Eur J Cardiothorac Surg, 2003, 23: 201-208. [Medline] [CrossRef]

15) McAlister FA, Bertsch K, Man J, et al.: Incidence of and risk factors fo pulmonary complications after nonthoracic surgery. Am J Respir Crit Care Med, 171, 514-517, 2005.
16) Yu JA, Pomerantz M, Bishop A, et al.: Lady Windermere revisited: treatment with thoracoscopic lobectomy/segmentectomy for right middle lobe and lingular bronchiectasis associated with non-tuberculous mycobacterial disease. Eur J Cardiothorac Surg, 2011, 40: 671-675. [Medline]

17) Varela G, Ballesteros E, Jiménez MF, et al.: Cost-effectiveness analysis of prophylactic respiratory physiotherapy in pulmonary lobectomy. Eur J Cardiothorac Surg, 2006, 29: 216-220. [Medline] [CrossRef]

18) Santambrogio L, Nosotti M, Baisi A, et al.: Pulmonary lobectomy for lung cancer: a prospective study to compare patients with forced expiratory volume in $1 \mathrm{~s}$ more or less than $80 \%$ of predicted. Eur J Cardiothorac Surg, 2001, 20: 684-687. [Medline] [CrossRef]

19) Spyratos D, Zarogoulidis P, Porpodis K, et al.: Preoperative evaluation for lung cancer resection. J Thorac Dis, 2014, 6: S162-S166. [Medline] 